\title{
Immune responses of Holstein and Norwegian Red $\times$ Holstein calves on Canadian dairy farms
}

\author{
N. Begley ${ }^{\star} †$ F. Buckley, ${ }^{* 1}$ E. B. Burnside,‡ L. Schaeffer,§ K. Pierce, $†$ and B. A. Mallard\# \\ ${ }^{\star}$ Teagasc, Dairy Production Research Centre, Moorepark, Fermoy, Co. Cork, Ireland \\ †School of Agriculture, Food and Veterinary Medicine, University College Dublin, Belfield, Dublin 4, Ireland \\ ¥Gencor, R.R. \#5, Guelph, Ontario, Canada, N1H6J \\ $\S$ Department of Animal and Poultry Science, University of Guelph, Ontario, Canada, N1G 2W1 \\ \#Ontario Veterinary College, University of Guelph, Ontario, Canada, N1G 2W1
}

\section{ABSTRACT}

The objective of this study was to compare the immune response of Holstein and Norwegian Red $x$ Holstein calves on 13 commercial Canadian dairy farms. Data were collected on 135 calves, 68 Holstein and 67 Norwegian Red $\times$ Holstein calves aged between 2 and 6 mo. The calves were immunized with hen egg white lysozyme to induce antibody-mediated immune response. Candida albicans was used as an in vivo indicator of cell-mediated immune response, with delayed-type hypersensitivity used as the indicator. Antibody response to hen egg white lysozyme (IgG, IgG1, and IgG2) was measured by ELISA. Calves of both breed groups produced a significant primary and secondary antibody-mediated immune response, as well as a delayed-type hypersensitivity reaction. The Norwegian Red $\times$ Holstein produced a greater primary $\operatorname{IgG}$ antibody-mediated immune response (d 14, and d 14 minus d 0) when compared with the Holstein. No differences were observed between the breeds for secondary response or anti-hen egg white lysozyme isotype (IgG1 or IgG2) production or the ratio of IgG1:IgG2. There was no effect of breed on delayed-type hypersensitivity. Nonetheless, high and low immune responders could be identified in both breed groups, but with no difference in the proportion of high and low responders observed for either antibody-mediated immune response or cellmediated immune response between breed groups.

Key words: Norwegian Red, crossbreeding, immune response

\section{INTRODUCTION}

Traditionally, dairy cattle breeding programs have emphasized selection on production and production-related traits. This seems to have contributed to decreased

Received April 25, 2008.

Accepted September 5, 2008.

${ }^{1}$ Corresponding author: frank.buckley@teagasc.ie animal health due to a negative genetic association between yield and udder health traits (Heringstad et al., 2003). In 1994, the Lifetime Profit Index in Canada had a weighting of $71 \%$ on production and $29 \%$ on durability (Leitch, 1994). In 2008, the Lifetime Profit Index weightings were changed to $51 \%$ on production, $34 \%$ on durability, and $15 \%$ on health and fertility (Canadian Dairy Network, 2008) to reflect increasing concerns about fertility, health, and calving performance in Canada. Similarly in the United States, the conception rate to first service has declined to about 30\% (Washburn et al., 2002). Clearly, methods that improve health and fertility traits merit further attention.

Crossbreeding can be a profitable option for dairy farmers (McAllister, 2002). Heins et al. (2006) have shown that crossbreeding with several breeds including the Scandinavian Red results in fewer days open when compared with pure Holstein. Both udder health and fertility have been incorporated into the selection program of the Norwegian Red (NR) since the 1970s (Heringstad et al., 2000). A selection experiment in Norway illustrated an improvement in general resistance to disease simultaneously with selection for improved resistance to mastitis (Heringstad et al., 2007). Walsh et al. (2007) also demonstrated superior udder health with NR cows compared with several other dairy breeds and crossbreds in a pasture-based environment. In the same study, the production potential of the NR cows was presented. Although statistically lower, compared with the Holstein-Friesian (HO) cows, the production potential of both breeds from a practical perspective under grazing conditions was not greatly divergent.

In future breeding programs, identification of animals with superior host defense mechanisms may help decrease the prevalence of mastitis and other infectious diseases (Wagter et al., 2000). Initial studies of antibody-mediated immune response (AMIR) and cellmediated immune response (CMIR) as indicators of improved host defense were carried out on mice (Biozzi et al., 1979), chickens (Pinard et al., 1992), and pigs (Mallard et al., 1992). Subsequent examination of dairy 
cows indicated that there is sufficient genetic variation between animals within a breed to allow breeding for AMIR and CMIR (Wagter et al., 2003). In 2 out of 3 herds tested during the periparturient period, there were lower incidences of mastitis and other diseases in high antibody responders (Wagter et al., 2003). Heritability estimates of 0.37 and 0.41 have been reported for AMIR and CMIR, respectively (Hernandez et al., 2006).

Although heritability estimates for bovine antibody isotypes have not yet been well documented, production of particular isotypes is critical to efficacious type 1 and type 2 immune responses (often previously referred to as T-helper 1 and 2; Estes and Brown, 2002). The T-helper 1 cells secrete inflammatory cytokines (e.g., IFN- $\gamma$ and IL-2) that activate components of the innate and adaptive immune system to defend against intracellular pathogens. The T-helper 2 cells secrete cytokines (e.g., IL-4, IL-5, IL-13) that are generally antiinflammatory in nature and are important for evoking potent antibody responses with particular isotype bias (Hodgkin et al., 1988). Nonnecke et al. (2005) demonstrated that early vaccination of calves was associated with a T-helper 1-like response to antigen comparable to the response of adult cattle sensitized in a similar manner.

A crossbreeding program in Canadian dairy herds was initiated to quantify the potential merits or economic benefits of crossbreeding $\mathrm{HO}$ females with the NR sires. As part of that program, the objectives of the current study were to evaluate immune response traits in these breed groups $[\mathrm{HO}$ and $\mathrm{NR} \times \mathrm{HO}(\mathbf{N R X})]$.

\section{MATERIALS AND METHODS}

\section{Animal Data Set and Immunization Procedures}

Calves were sourced through Gencor Inc. (Guelph, Ontario, Canada) and CanWest DHI (Guelph, Ontario, Canada), who had provided a list of producers that had used NR semen. Table 1 provides details of the breed, age, and sex of the calves tested on each farm. In total, immune response was evaluated on $68 \mathrm{HO}$ and 67 NRX male and female calves across 13 commercial dairy herds in southern Ontario, Canada. All herds provided both $\mathrm{HO}$ and NRX calves. Herds were selected based on the availability of HO and NRX calves aged between 2 and 6 mo. This age group was chosen to decrease the influence of passive maternal immunity. The antigen used [hen egg white lysozyme (HEWL)] in the study was chosen because it should not be present in maternal colostrum. Recent studies have indicated that calves aged $8 \mathrm{wk}$ and greater have a CMIR that is more characteristic of an adult response (Foote et al., 2005). This overcomes any bias due to a different degree of maturation of the immune response. The average age of the breed groups was $3.67 \mathrm{mo}( \pm 1.08)$ and $3.75 \mathrm{mo}$ $( \pm 1.29)$ for the HO and the NRX, respectively. Data were collected from July through November 2006. Twenty-two of the 135 calves were male (10 NRX and $12 \mathrm{HO}$ ). The NRX were sired by $5 \mathrm{NR}$ sires, whereas the $\mathrm{HO}$ calves were sired by 36 different $\mathrm{HO}$ sires.

Calves were immunized to induce AMIR and delayedtype hypersensitivity (DTH) with slight modification to that described previously for adult cows (Wagter et al., 2000; Hernandez et al., 2003). Briefly, calves received intramuscularly HEWL (Sigma, Oakville, Ontario, Canada; $0.5 \mathrm{mg}$ ), along with the DTH-inducing antigen, Candida albicans (Greer Laboratories, Hornby, Ontario, Canada; $0.5 \mathrm{mg}$ ), in QuilA adjuvant (Cedarlane, Burlington, Ontario, Canada; $0.5 \mathrm{mg}$ ) combined in a total volume of $1.0 \mathrm{~mL}$ of PBS ( $\mathrm{pH} 7.4$ ) on d 0 and 14. Blood samples were taken on d 0 (baseline), 14 (primary response), and 21 (secondary response). Serum was derived from the blood samples each day and stored at $-20^{\circ} \mathrm{C}$.

Delayed-type hypersensitivity was used as an in vivo indicator of CMIR following protocols optimized for calves described previously (Hernandez et al., 2005). A previous Canadian study by Hernandez et al. (2006) estimated heritability of this trait at 0.40 , and also determined minimal preexisting antibody against $C$. albicans demonstrating its usefulness as a DTH test antigen. The same study also demonstrated that $C$. albicans elicits a strong CMIR response in dairy cattle. Background skin thickness measurements were taken on d 21 (3 replicates) at the tail fold using Harpenden skin callipers (Creative Health Products Inc., Ann Arbor, MI). Delayed-type hypersensitivity was subsequently elicited using the intradermal skin test as follows: calves were challenged with $0.1 \mathrm{mg}$ of $C$. albicans dissolved in $0.1 \mathrm{~mL}$ of PBS into the right side of the tail head, and as a control, $0.1 \mathrm{~mL}$ of PBS was injected into the left side of the tail head. An increase in double skin fold thickness was indicative of the magnitude of DTH when measurements were taken at control and test antigen sites after $48 \mathrm{~h} \mathrm{(d} \mathrm{23).} \mathrm{This} \mathrm{has} \mathrm{been} \mathrm{shown} \mathrm{to} \mathrm{be} \mathrm{the}$ optimal time to receive maximum response (Hernandez et al., 2005) Values were expressed as millimeter increase in thickness from 0 to $48 \mathrm{~h}$, while also taking any increases in the control into account:

$$
\text { Increase }(\mathrm{mm})=(\mathrm{A}-\mathrm{B})-(\mathrm{C}-\mathrm{D})
$$

where $\mathrm{A}=$ mean test thickness (at time $=48 \mathrm{~h}) ; \mathrm{B}=$ mean of pretest thickness (at time $=0 \mathrm{~h}$ ); $\mathrm{C}=$ mean of control thickness (at time $=48 \mathrm{~h}$ ); and $\mathrm{D}=$ mean of precontrol thickness (at time $=0 \mathrm{~h}$ ). 
Table 1. Breed group, age, and sex distribution of calves by herd

\begin{tabular}{|c|c|c|c|c|c|c|c|c|}
\hline \multirow[b]{2}{*}{ Herd } & \multirow[b]{2}{*}{ Breed group ${ }^{1}$} & \multicolumn{4}{|c|}{ Age (mo) } & \multicolumn{2}{|c|}{ Sex } & \multirow[b]{2}{*}{ Total } \\
\hline & & $<3$ & 3 to 4 & 4 to 5 & $>5$ & Female & Male & \\
\hline \multirow[t]{2}{*}{1} & $\mathrm{HO}$ & 2 & 7 & 2 & 1 & 6 & 6 & 12 \\
\hline & NRX & 2 & 6 & 1 & 1 & 4 & 6 & 10 \\
\hline \multirow[t]{2}{*}{2} & $\mathrm{HO}$ & 4 & 0 & 0 & 0 & 4 & 0 & 4 \\
\hline & NRX & 3 & 0 & 0 & 1 & 4 & 0 & 4 \\
\hline \multirow[t]{2}{*}{3} & $\mathrm{HO}$ & 0 & 0 & 1 & 1 & 2 & 0 & 2 \\
\hline & NRX & 0 & 2 & 0 & 0 & 2 & 0 & 2 \\
\hline \multirow[t]{2}{*}{4} & $\mathrm{HO}$ & 0 & 2 & 0 & 2 & 4 & 0 & 4 \\
\hline & NRX & 3 & 0 & 1 & 0 & 4 & 0 & 4 \\
\hline \multirow[t]{2}{*}{5} & $\mathrm{HO}$ & 0 & 3 & 1 & 0 & 4 & 0 & 4 \\
\hline & NRX & 1 & 1 & 2 & 0 & 4 & 0 & 4 \\
\hline \multirow[t]{2}{*}{6} & $\mathrm{HO}$ & 1 & 0 & 0 & 1 & 2 & 0 & 2 \\
\hline & NRX & 1 & 0 & 0 & 1 & 2 & 0 & 2 \\
\hline \multirow[t]{2}{*}{7} & $\mathrm{HO}$ & 0 & 1 & 0 & 1 & 2 & 0 & 2 \\
\hline & NRX & 1 & 0 & 0 & 5 & 6 & 0 & 6 \\
\hline \multirow[t]{2}{*}{8} & $\mathrm{HO}$ & 1 & 1 & 2 & 1 & 0 & 5 & 5 \\
\hline & NRX & 1 & 4 & 3 & 2 & 6 & 4 & 10 \\
\hline \multirow[t]{2}{*}{9} & $\mathrm{HO}$ & 1 & 2 & 1 & 0 & 4 & 0 & 4 \\
\hline & NRX & 2 & 1 & 0 & 0 & 3 & 0 & 3 \\
\hline \multirow[t]{2}{*}{10} & $\mathrm{HO}$ & 1 & 0 & 0 & 1 & 2 & 0 & 2 \\
\hline & NRX & 1 & 0 & 0 & 1 & 2 & 0 & 2 \\
\hline \multirow[t]{2}{*}{11} & $\mathrm{HO}$ & 0 & 3 & 2 & 1 & 6 & 0 & 6 \\
\hline & NRX & 4 & 2 & 0 & 0 & 6 & 0 & 6 \\
\hline \multirow[t]{2}{*}{12} & $\mathrm{HO}$ & 2 & 5 & 0 & 0 & 6 & 1 & 7 \\
\hline & NRX & 1 & 1 & 2 & 0 & 4 & 0 & 4 \\
\hline \multirow[t]{2}{*}{13} & $\mathrm{HO}$ & 6 & 3 & 4 & 1 & 14 & 0 & 14 \\
\hline & NRX & 4 & 2 & 3 & 1 & 10 & 0 & 10 \\
\hline Total & & 41 & 46 & 26 & 22 & 113 & 22 & \\
\hline
\end{tabular}

${ }^{1} \mathrm{HO}=$ Holstein NRX $=$ Norwegian Red $\times$ Holstein.

\section{Serum Antibody}

Antibody response to HEWL was measured using an ELISA method described previously (Wagter et al., 2000). Sera, including negative and positive control samples (to be used as standards on each plate), were diluted 1:50 and 1:300 in PBS and 0.05\% Tween 20 (Scientific, Don Mills, Ontario, Canada) wash buffer (pH 7.4). Serum samples were measured in quadruplicate allowing 10 samples to be analyzed per plate. Rabbit anti-bovine IgG was used at a dilution of 1:10,000. Negative and positive controls were obtained by pooling samples of sera from calves preimmunization and from sera postimmunization (d 21), respectively. Bovine anti-HEWL IgG1 and IgG2 were also measured using a similar ELISA with serum samples of 1:50 and 1:300. Sheep anti-bovine antibody alkaline phosphataseconjugated IgG1 and IgG2 (Cedarlane, Burlington, Ontario, Canada) were added at dilution of 1:200 and 1:120, respectively.

Antibody concentration was estimated by optical density (OD) using an EL311 automatic ELISA plate reader (Bio-Tek Instruments, Highland Park, VT). The OD was recorded at 405 and $630(\mathrm{~nm})$ when the positive control reached OD $>0.999$. Values were corrected to an $\mathrm{OD}=1.0$ as described previously (Wagter et al., 2000). Corrected means of each dilution were then added together to give an additive OD value. To maintain a CV of not greater than $10 \%$, if the CV of the positive and negative samples on the plate were greater than $10 \%$, the samples were reanalyzed. If an individual sample on the plate had a CV of greater than $10 \%$, this sample was reanalyzed.

\section{Data Analyses}

Data were analyzed using PROC GLM (SAS Institute, 2006). Statistical analyses were carried out to examine anti-HEWL IgG, IgG1, and IgG2 (AMIR) on d 0,14, and 21. Specific antibody responses were examined based on OD value at each time point. Primary response was determined by the concentration of anti-HEWL on d 14 and the percentage increase in anti-HEWL IgG production from d 0 to 14. Similarly, secondary response was evaluated as the concentration of anti-HEWL IgG on d 21 and the percentage increase in anti-HEWL IgG production from d 14 to 21 (Wagter et al., 2000). Delayed-type hypersensitivity (CMIR) was evaluated at $48 \mathrm{~h}$ postimmunization. Observations were log-transformed (natural log) to ensure normalization of the residuals. The transformed data satisfied the assumptions of ANOVA and were used to calculate 
$P$-values. The corresponding least squares means, however, and standard errors of the nontransformed data are presented in the results for clarity. The age of the calves was between 2 and 6 mo. For the purposes of statistical analysis, 4 categories were formed $(<3 \mathrm{mo}$, 3 to $4 \mathrm{mo}, 4$ to $5 \mathrm{mo},>4 \mathrm{mo}$ ). The average age of the calves $<3$ mo was 71.8 and $72.7 \mathrm{~d}$ for the $\mathrm{HO}$ and the NRX, respectively. The model was

$$
\mathrm{Y}_{\mathrm{ijklm}}=\operatorname{herd}_{\mathrm{i}}+\operatorname{age}_{\mathrm{j}}+\operatorname{sex}_{\mathrm{k}}+\operatorname{breed}_{\mathrm{l}}+\mathrm{e}_{\mathrm{ijklm}}
$$

where herd $\mathrm{i}_{\mathrm{i}}=$ fixed effect of herd (farm 1 to 13$) ;$ age $_{\mathrm{j}}=$ fixed effect of age ( $3 \mathrm{mo}, 3$ to $4 \mathrm{mo}, 4$ to $5 \mathrm{mo},>4 \mathrm{mo}$ ); $\operatorname{sex}_{\mathrm{k}}=$ fixed effect of calf sex (male or female); breed $_{1}=$ fixed effect of breed (HO or NRX); and $\mathrm{e}_{\mathrm{ijklm}}=$ residual error term.

Comparisons of primary and secondary AMIR responses, as denoted by the change in concentrations of anti-HEWL IgG between d 0 and 14 and d 14 and 21 , respectively, within breed were calculated using Student's $t$-test. High responders were defined as calves that were 1 standard deviation above the population mean value, and low responders were defined as calves that had residuals 1 standard deviation below the mean value (Wagter et al., 2000; Hernandez et al., 2005). These values were estimated using the residuals from the model (observations minus estimated effects for herd, age, sex, and breed). Differences in the proportion of high and low responders between genotypes were compared using a $\chi^{2}$ analysis.

\section{RESULTS}

\section{Anti-HEWL Total IgG Antibody}

Figure 1 reports the effect of breed on the production of anti-HEWL IgG, IgG1, and IgG2. On d 0, no differences were observed between the breed groups for anti-HEWL total IgG antibody concentration with OD values of $0.055( \pm 0.035)$ with values ranging between 0.026 and 0.23 and a CV of $7.9 \%$, and $0.052( \pm 0.025)$ ranging from 0.03 to 0.16 with a $\mathrm{CV}$ of $5.8 \%$, for the $\mathrm{HO}$ and the NRX, respectively.

On d 14, the NRX produced greater concentrations of anti-HEWL IgG at $0.41( \pm 0.25)$ OD $(P<0.05)$ compared with the $\mathrm{HO}$ at $0.30( \pm 0.19) \mathrm{OD}$. The range of OD values was 0.05 to 0.86 for the $\mathrm{HO}$ with a $\mathrm{CV}$ of $7.6 \%$ and ranging from 0.05 to 0.98 with a $\mathrm{CV}$ of $7.7 \%$ for the NRX.

The primary response expressed as the percentage increase in production of anti-HEWL IgG from d 0 to 14 was greater $(P<0.05)$ for the NRX at $753 \%$ compared with the $\mathrm{HO}$ at $542 \%$. The $\mathrm{CV}$ were 10 and $11 \%$ for the NRX and the HO, respectively.
There was no difference in the concentration of antiHEWL IgG on d 21 between the HO and the NRX (Figure 1). Mean values of $1.03( \pm 0.20)$ and $1.04( \pm 0.22)$ were observed for the $\mathrm{HO}$ and the NRX, respectively. The range of OD values was similar for both breeds ranging from 0.63 to 1.97 for the $\mathrm{HO}$, with a $\mathrm{CV}$ of $2.4 \%$, and 0.41 to 1.96 for the NRX, with a CV of $2.6 \%$.

The secondary response calculated as the percentage increase in production of anti-HEWL IgG from $\mathrm{d}$ 14 to 21 was significant for both breed groups $(P<$ $0.001)$, but the response was greater in the HO $(P<$ 0.05 ) at $438 \%$ compared with the NRX at $382 \%$ (Table 2 ). When the model was adjusted for anti-HEWL IgG production on d 14, no differences between the breed groups for secondary response were detected.

\section{Anti-HEWL IgG1, IgG2, and IgG1:IgG2 Antibody}

There was no difference between breeds for the production of anti-HEWL antibody isotypes IgG1 and IgG2 (Table 3 ). The ratio of IgG1:IgG2 was also investigated to evaluate if either group had a type 1 or type 2 isotype bias, but no differences were observed between breeds (Table 4). On d 14, the ratio of IgG1:IgG2 was $1.70( \pm 2.14)$ and $1.83( \pm 1.74)$ for the HO group and the NRX, respectively. The range of values was similar across both breeds, with the HO ranging from 0.08 to 9.69, with a CV of $13.7 \%$ and the NRX ranging from 0.04 to 9.04 , with a $\mathrm{CV}$ of $10.9 \%$. Although not significant, on d 21, the HO had an IgG1:IgG2 ratio of 1.20 $( \pm 0.64)$ compared with the NRX, whose ratio was 1.08 $( \pm 1.09)$. The range of values was greater for the NRX ranging from 0.34 to 9.30 compared with values of 0.30 to 3.12 for the HO. The CV was 6.9 and $12.5 \%$ for the $\mathrm{HO}$ and the NRX, respectively.

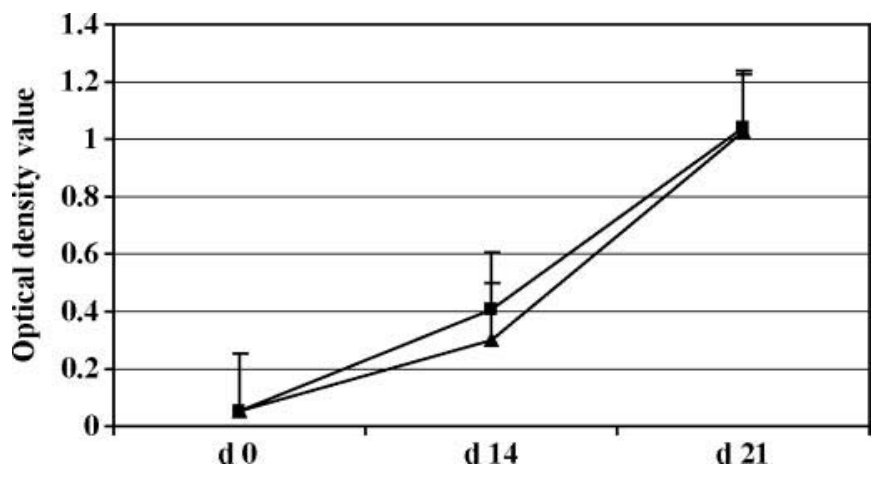

Figure 1. Production of anti-hen egg white lysozyme IgG antibody expressed as optical density values for Holstein $(\boldsymbol{\Lambda})$ and Norwegian Red $\times$ Holstein $(\mathrm{NRX})(\boldsymbol{\square})$ calves on d 0, 14, and 21 . 
Table 2. Breed difference between the Holstein (HO) and Norwegian Red $\times$ Holstein $($ NRX) crossbred calves for primary and secondary response expressed as percentage increase in anti-hen egg white lysozyme (HEWL) IgG production

\begin{tabular}{lcccc}
\hline Item & HO & NRX & SE & $P$-value \\
\hline Primary response $\%^{1}$ & 543 & 754 & 108.7 & $<0.05$ \\
Secondary response $\%^{2}$ & 438 & 382 & 63.9 & $<0.05^{3}$ \\
\hline
\end{tabular}

${ }^{1}$ Primary response $=$ increase in anti-HEWL IgG production from $\mathrm{d}$ 0 .

${ }^{2}$ Secondary response $=$ increase in anti-HEWL IgG production from d 14 to 21 .

${ }^{3}$ This probability value was not significant $(P>0.05)$ when d 14 was used in the model as a covariate.

\section{Cell-Mediated Immune Response}

No significant differences were evident between breed groups for DTH response (Table 3) with a double skin fold increase of $4.56 \mathrm{~mm}( \pm 2.08)$ ranging from 0.28 to $10.47 \mathrm{~mm}$ and $4.46 \mathrm{~mm}( \pm 1.77)$ ranging from 0.24 to $8.80 \mathrm{~mm}$ for the HO and the NRX, respectively. The CV were $6.7 \%$ for the HO and $5.7 \%$ for the NRX.

\section{High and Low Immune Responders}

No significant differences were observed between the breeds for the proportion of high and low responders. On d 14, twenty calves, including 10 of each breed group, were defined as high responders. There were 15 of the NRX and 9 of the HO calves defined as low responders. For the production on anti-HEWL IgG on d 21, three HO and 3 NRX calves were high responders. A significantly greater proportion $(P<0.05)$ of NRX were low responders for $\mathrm{d} 21$, with the NRX having 11 low responders compared with the HO having 4 low responders. Two calves (1 HO and $1 \mathrm{NRX}$ ) were high for both anti-HEWL IgG production on d 14 and 21. For the production of anti-HEWL IgG on d 14 and 21, seven calves including $2 \mathrm{HO}$ and $5 \mathrm{NRX}$ were defined as low responders.
Eleven of the HO and 9 of the NRX were high responders for DTH. Additionally, $9 \mathrm{HO}$ and 8 NRX were low responders.

When the production of anti-HEWL IgG on d 14 and DTH were combined, 2 calves were defined as high responders; these were both from the HO group. One calf $(\mathrm{HO})$ from the 135 on the study was defined as a high responder for anti-HEWL IgG on d 21 and DTH. This calf was also high for anti-HEWL IgG on d 14 . Three calves (2 HO and 1 NRX) were defined as low responders for anti-HEWL IgG on d 14 and DTH. A total of 3 animals were low for the production of antiHEWL IgG on d 21 and DTH (2 NRX and 1 HO), with 1 of these animals (HO) also low for the production of anti-HEWL IgG on d 14.

\section{Herd, Age, and Calf Sex}

There was a significant effect of herd on anti-HEWL IgG and IgG1 production, as well as for DTH. Herd had no effect on anti-HEWL IgG2. Calf sex had no effect on any of the parameters investigated. Age, however, had a significant effect on the production of anti-HEWL IgG on $\mathrm{d} 0$, with calves $<3$ mo producing less anti-HEWL IgG compared with calves aged 4 to 5 mo $(P=0.06)$ and $>5$ mo $(P<0.01)$. Age had no effect on subsequent antibody production. Age also had an effect on DTH, similar to that of d 0 , with calves $<3$ mo having a response of $3.76 \mathrm{~mm}$ compared with calves 4 to $5 \mathrm{mo}$ and $>5$ mo who had a significantly greater increase in skin thickness at $4.68 \mathrm{~mm}(P<0.05)$ and $5.93 \mathrm{~mm}(P$ $<0.01$ ), respectively.

\section{DISCUSSION}

The objective of the study was to provide an initial comparison of immune responses of HO and NRX calves on Canadian commercial dairy farms. Enhancing immune responsiveness via breeding programs has the potential to improve both health and production traits (Wilkie and Mallard, 1999). Various phenotypic and

Table 3. Production of anti-hen egg white lysozyme (HEWL) IgG1 and IgG2 antibody expressed as optical density values and delayed-type hypersensitivity (DTH) measured as millimeter increase in skin fold thickness after $48 \mathrm{~h}$ for Holstein $(\mathrm{HO})$ and Norwegian Red $\times$ Holstein $(\mathrm{NRX})$ calves

\begin{tabular}{lcccc}
\hline Item & HO & NRX & SE & $P$-value \\
\hline Anti-HEWL IgG1 d 0 & 0.06 & 0.06 & 0.004 & $\mathrm{NS}^{1}$ \\
Anti-HEWL IgG1 d 14 & 0.29 & 0.35 & 0.040 & NS \\
Anti-HEWL IgG1 d 21 & 1.07 & 1.02 & 0.043 & NS \\
Anti-HEWL IgG2 d 0 & 0.06 & 0.09 & 0.023 & NS \\
Anti-HEWL IgG2 d 14 & 0.34 & 0.27 & 0.050 & NS \\
Anti-HEWL IgG2 d 21 & 1.18 & 1.28 & 0.087 & NS \\
DTH (mm) & 4.56 & 4.46 & 0.295 & NS \\
\hline
\end{tabular}

${ }^{1} P>0.05$. 
Table 4. Anti-hen egg white lysozyme (HEWL) IgG1:IgG2 ratio expressed as optical density values for Holstein $(\mathrm{HO})$ and Norwegian $\times$ Red Holstein (NRX) crossbred calves

\begin{tabular}{lcccc}
\hline Item & HO & NRX & SE & $P$-value \\
\hline Anti-HEWL IgG1:IgG2 d 0 & 1.16 & 1.15 & 0.103 & NS $^{1}$ \\
Anti-HEWL IgG1:IgG2 d 14 & 1.68 & 1.85 & 0.375 & NS \\
Anti-HEWL IgG1:IgG2 d 21 & 1.20 & 1.09 & 0.170 & NS \\
\hline
\end{tabular}

${ }^{1} P>0.05$.

genetic markers for disease resistance have been suggested (Rupp and Boichard, 2003). Due to the capability of pathogens to vary their virulence mechanisms, the success of targeting a few specific genes to enhance general health has been questioned (Wilkie et al., 1998; Hernandez et al., 2003). Complex infectious diseases and common groups of pathogens are generally controlled by more than one gene (Wilkie and Mallard, 1999). Breeding programs, including crossbreeding that alters multiple genes simultaneously, therefore, may be most effective, at least until more genes and their interactions are better understood, or until large single nucleotide polymorphism chips are available for genome-wide marker-assisted selection of livestock (Goddard and Hayes, 2002; Hernandez et al., 2006).

Targeting the immune system offers an avenue to increase disease resistance given its role in host defense (Abdel-Azim, 2005). Antibody-mediated immune response and CMIR have been shown to have beneficial effects with studies in pigs demonstrating both health and production benefits (Wilkie and Mallard, 1999). Subsequently, these traits were chosen for evaluation in $\mathrm{HO}$ and NRX calves in this study. The limited sample size of this initial study prevents direct conclusions pertaining to genetic associations. The main focus here, however, relates to the observed phenotypic variation.

The results indicated that the NRX calves had the ability to produce a greater primary antibody response compared with the $\mathrm{HO}$, with a greater concentration of anti-HEWL IgG on d 14 and a greater percentage increase in anti-HEWL IgG from d 0 to 14 . This suggests that the NRX may have a better ability to respond quickly to infection in the face of an initial challenge. Both breed groups, however, displayed the capacity to mount a significant secondary immune response (d 14 to 21). Previous studies carried out on mice have shown that selection for high or low antibody production to sheep red blood cells is inversely associated with CMIR. The same study, along with others, demonstrated that high antibody production was associated with the control of extracellular pathogens, but not necessarily intracellular pathogens (Biozzi et al., 1979). It is preferable, therefore, to identify animals that are high responders for both traits (Mallard et al., 1992; Hernandez et al., 2006). This should lead to a more balanced immune response with better control of intracellular and extracellular pathogens (Wilkie et al., 1998; Hernandez et al., 2003). Bias to AMIR or CMIR may be useful in certain types of breeding programs in which diverse lines can be maintained or certain types of diseases are particularly prevalent (Pinard et al., 1992). Generally, it is better to avoid extreme type 1 or type 2 immune response bias to prevent resistance to one set of pathogens at the expense of susceptibility to others (Wilkie and Mallard, 1999). In the current study, no differences were seen in Ig isotype bias or DTH, suggesting no differences in type 1 or type $2 \mathrm{im}$ mune responses between breeds. However, there was increased bias toward anti-HEWL IgG1 production on d 14 when compared to d 0 and 21. This could influence host defense to various pathogens but would need further investigation. Given the breed differences noted in this study, subsequent examination is warranted with larger numbers of calves to establish estimates of heritability and heterosis of immune response traits in the context of crossbreeding of $\mathrm{HO}$ dairy cattle.

Considering that AMIR and CMIR appear to be independent genetic traits (Rupp et al., 2007) and have been reported on occasion to be in negative association (Wilkie and Mallard, 1999; Hernandez et al., 2006), it is difficult to find animals superior for both traits. Nonetheless, a previous selection experiment in pigs demonstrated that it is possible to simultaneously improve both AMIR and CMIR (Mallard et al., 1992). In the current study, only 1 calf (HO) out of 135 was a high responder for all 3 traits investigated (anti-HEWL IgG d 14 and d 21, and DTH). Other animals were either high or low responders for one or other of the traits and were within one standard deviation of the mean for the other traits.

From this study, it cannot be determined whether the primary antibody response differences are due to the effect of the NR sires or crossbreeding. The Norwegian selection program incorporates selection for improved health. Crossbreeding results in hybrid vigor, and estimates of heterosis up to $20 \%$ for health traits have been reported (Swan and Kinghorn, 1992). Maltecca et al. (2006) showed that crossbred Jersey calves had decreased perinatal and preweaning mortality compared with HO. There was also evidence that HO 
calves had greater fecal consistency scores than Jersey crossbred calves, which is associated with increased scours (Maltecca and Weigel, 2004). In Norway, health traits have been incorporated into the selection criteria since the 1970s. A selection experiment in Norway illustrated an improvement in general resistance to disease simultaneous with selection for improved resistance to mastitis (Heringstad et al., 2007). This selection may have resulted in altered immune responses among other disease-related traits.

Research by Corbeil et al. (2006) showed that calves begin to recover from pneumonia when IgG2 concentrations peak. A recent study by Weigel et al. (2006) reported that crossbred Jersey calves had greater serum protein and IgG concentrations compared with pure Holstein calves $24 \mathrm{~h}$ after birth. The current study also showed differences in primary IgG antibody between purebred and NRX calves. This may contribute to the improvements previously noted in other health traits, such as mastitis and SCC in the NR and related crossbreds. A recent on-farm study has shown that NRX have lower SCC and a lesser incidence of mastitis when compared with $\mathrm{HF}$ in first lactation (Begley et al., 2007). The current study demonstrated differences in specific antibody response between purebred $\mathrm{HO}$ and NR crossbred calves indicating that further examination of immune response traits is warranted in crossbred dairy cattle. In fact, the female calves in this study will subsequently be evaluated for AMIR and CMIR as first and second parity cows.

\section{CONCLUSIONS}

This study provides some insight into the ability of calves, aged between 2 and 6 mo, to produce a response following the induction of both AMIR and CMIR. Crossbreeding $\mathrm{HO}$ with the NR was associated with an increased primary IgG antibody response, but not secondary antibody response or DTH. This may have implications for improved host defense and health, particularly when AMIR is relevant to protection, as is the case for most extracellular pathogens. The findings of this study could be due to an additive genetic effect following selection for improved health within the NR breed or could be due to the effects of crossbreeding. The observed variation and the ability to identify high and low responders suggest that these traits have potential, given their role in host protection, to improve calf health. Crossbreeding of dairy cattle, combined with the ability to identify high and low responders, may be useful. A lack of data available currently, however, means further studies to estimate repeatability of these indicator traits as well as associations between these traits and incidences of disease are required to clarify their usefulness.

\section{ACKNOWLEDGMENTS}

The financial support from the Research Stimulus Fund (RSF-06-353), Natural Sciences and Engineering Research Council of Canada, and the assistance of Gencor Inc. (Guelph, Ontario, Canada) is gratefully acknowledged. The technical help and cooperation of Shannon Cartwright, Laura Clark, Armando Hernandez (all at University of Guelph), and Marlene Paibomesai (OMAFRA, Ontario, Canada) is greatly appreciated.

\section{REFERENCES}

Abdel-Azim, G. A. 2005. Genetic basis and risk factors for infectious and non-infectious diseases in US Holsteins. I. Estimation of genetic parameters for single diseases and general health. J. Dairy Sci. 88:1199-1207.

Begley, N., M. Rath, and F. Buckley. 2007. Milk production, udder health, body condition score at breeding and fertility of first lactation Holstein-Friesian, Norwegian Red and Holstein-Friesian $\times$ Norwegian Red cows on Irish dairy farms. Page 314 in Proc. 58th Meet. Eur. Assoc. Anim. Prod., Dublin, Ireland. Wageningen Acad. Publ., Wageningen, the Netherlands.

Biozzi, G., D. Mouton, A. Heuman, Y. Bouthillier, C. Stiffel, and J. C. Mevel. 1979. Genetic analysis of antibody responsiveness to sheep erythrocytes in crosses between lines of mice selected for high or low antibody synthesis. Immunology 36:427-438.

Canadian Dairy Network (CDN). 2008. Lifetime profit index (LPI) formula. http://www.cdn.ca/articles.php Accessed Nov. 11, 2008.

Corbeil, L. B., K. F. Arnold, R. Kimball, L. Berghaus, and L. J. Gershwin. 2006. Specificity of $\mathrm{IgG}$ and $\mathrm{IgE}$ antibody responses to Haemophilus somnus infection of calves. Vet. Immunol. Immunopathol. 113:191-199.

Estes, D. M., and W. C. Brown. 2002. Type 1 and type 2 responses in regulation of $\mathrm{Ig}$ isotype expression in cattle. Vet. Immunol. Immunopathol. 90:1-10.

Foote, M. R., B. J. Nonnecke, M. A. Fowler, B. L. Miller, D. C. Beitz, and W. R. Waters. 2005. Effects of age and nutrition on expression of CD25, CD44, and L-selection (CD62L) on T-cells from neonatal calves. J. Dairy Sci. 88:2718-2729.

Goddard, M. E., and B. J. Hayes. 2002. Optimisation of response using molecular data. Proc 7th World Congr. Genet. Appl. Livest. Prod., Montpellier, France. CD-ROM Communication 22-01.

Heins, B. J., L. B. Hansen, and A. J. Seykora. 2006. Calving difficulty and stillbirths of pure Holsteins versus crossbreds of Holstein with Normande, Montbeliarde, and Scandinavian Red. J. Dairy Sci. 89:2805-2810.

Heringstad, B., Y. M. Chang, D. Gianola, and G. Klemetsdal. 2003. Genetic analysis of longitudinal trajectory of clinical mastitis in first-lactation Norwegian Red cattle. J. Dairy Sci. 86:2676-2683.

Heringstad, B., G. Klemetsdal, and J. Ruane. 2000. Selection for mastitis resistance: A review with focus on the situation in the Nordic countries. Livest. Prod. Sci. 64:95-106.

Heringstad, B., G. Klemetsdal, and T. Steine. 2007. Selection responses for disease resistance in two selection experiments with Norwegian Red cows. J. Dairy Sci. 90:2419-2426.

Hernandez, A., N. Karrow, and B. A. Mallard. 2003. Evaluation of immune responses of cattle as a means to identify high or low responders and use of a human microarray to differentiate gene expression. Genet. Sel. Evol. 35(Suppl. 1):S67-S81.

Hernandez, A., V. M. Quinton, F. Miglior, and B. A. Mallard. 2006. Genetic parameters of dairy cattle immune response traits. Proc. 
8th World Congr. Genet. Appl. Livest. Prod., Belo Horizonte, Minas Gerais, Brazil.

Hernandez, A., J. A. Yager, B. N. Wilkie, K. E. Leslie, and B. A. Mallard. 2005. Evaluation of bovine cutaneous delayed-type hypersensitivity (DTH) to various test antigens and a mitogen using several adjuvants. Vet. Immunol. Immunopathol. 104:4558.

Hodgkin, P. D., M. W. Bond, A. O'Garra, G. Frank, F. Lee, R. L. Coffman, A. Zlotnik, and M. Howard. 1988. Identification of IL-6 as a $\mathrm{T}$ cell derived factor that enhances the proliferative response of thymocyte to IL-4 and phorbal myrustste acetate. J. Immunol. 141:151-157.

Leitch, H.W. 1994. Comparison of international selection indices for dairy cattle breeding. Interbull. Bull. No. 10. Interbull, Uppsala, Sweden.

Mallard, B. A., B. N. Wilkie, B. W. Kennedy, and M. Quinton. 1992. Use of estimated breeding values in a selection index to breed Yorkshire pigs for high and low immune and innate resistance factors. Anim. Biotechnol. 3:257-280.

Maltecca, C., H. Khatib, V. R. Schutzkus, P. C. Hoffman, and K. A. Weigel. 2006. Changes in conception rate, calving performance, and calf health and survival from the use of crossbred Jersey $x$ Holstein sires as mates for Holstein dams. J. Dairy Sci. 89:27472754.

Maltecca, C., and K. A. Weigel. 2004. Health parameters in F1 Jersey $\times$ Holstein, backcross (Jersey $\times$ Holstein $) \times$ Holstein and pure Holstein calves. J. Dairy Sci. 87(Suppl. 1):87. (Abstr.)

McAllister, A. J. 2002. Is crossbreeding the answer to questions of dairy breed utilization? J. Dairy Sci. 85:2352-2357.

Nonnecke, B. J., W. R. Waters, M. R. Foote, M. V. Palmer, B. L. Miller, T. E. Johnson, H. B. Perry, and M. A. Fowler. 2005 Development of an adult-like cell-mediated immune response in calves after early vaccination with Mycobacterium bovis bacillus Calmette-Guérin. J. Dairy Sci. 88:195-210.

Pinard, M. H., J. A. M. van Arendonk, M. G. B. Nieuwland, and A. J. van der Zijpp. 1992. Divergent selection for immune responsiveness in chickens: Estimation of realized heritability with an animal model. J. Anim. Sci. 70:2986-2993.
Rupp, R., and B. Boichard. 2003. Genetics of resistance to mastitis in dairy cattle. Vet. Res. 34:671-688

SAS Institute. 2006. User's Guide: Statistics. SAS Institute, Cary, $\mathrm{NC}$

Swan, A. A., and B. P. Kinghorn. 1992. Evaluation and exploitation of crossbreeding in dairy cattle. J. Dairy Sci. 75:624-639.

Wagter, L. C., B. A. Mallard, B. N. Wilkie, K. E. Leslie, P. J. Boettcher, and J. C. M. Dekkers. 2000. A quantitative approach to classifying Holstein cows based on antibody responsiveness and its relationship to peripartum mastitis occurrence. J. Dairy Sci. $83: 488-498$

Wagter, L. C., B. A. Mallard, B. N. Wilkie, K. E. Leslie, P. J. Boettcher, and J. C. M. Dekkers. 2003. The relationship between milk production and antibody response to ovalbumin during the peripartum period. J. Dairy Sci. 86:169-173.

Walsh, S., F. Buckley, D. P. Berry, M. Rath, K. Pierce, N. Byrne, and P. Dillon. 2007. Effect of breed, feeding system and parity on udder health and milking characteristics. J. Dairy Sci. 90:5767-5779.

Washburn, S. P., S. L. Whyte, J. T. Green Jr., and G. A. Benson. 2002 Reproduction, mastitis, and body condition score of seasonally calved Holstein and Jersey cows in confinement or pasture systems. J. Dairy Sci. 85:105-111.

Weigel, K. A., C. Maltecca, H. Khatib, V. R. Scutzkus, and P. C. Hoffman. 2006. Health, immune function and survival of Holstein and Jersey $\times$ Holstein dairy calves. Proc. 8th World Congr. Genet. Appl. Livest. Prod., Belo Horizonte, Minas Gerais, Brazil.

Wilkie, B. N., and B. A. Mallard. 1999. Selection for high immune response: An alternative approach to animal health maintenance? Vet. Immunol. Immunopathol. 72:231-235.

Wilkie, B. N., B. A. Mallard, M. Quinton, and J. Gibson. 1998. Multitrait selection for immune response: A possible alternative strategy for enhanced livestock health and productivity. Pages 29-38 in Progress in Pig Science. J. Wiseman, M. A. Varley, and J. P. Chadwick, ed. Nottingham University Press, Nottingham, UK. 